\title{
Correlation Between Professionalism, Job Satisfaction and Job Performance of the Physical Therapist
}

\author{
Seung Kyu Park', Jae Won Heo ${ }^{2}$ \\ 'Department of Physical Therapy, School of Public Health, Sehan University, ${ }^{2}$ Department of Physical Therapy, Graduate School, Sehan University, \\ Yeongam-gun, Jeollanam-do, Korea
}

Purpose: This study was conducted in order to understand the correlation between professionalism, job satisfaction, and job performance of physical therapists

Methods: Subjects included 148 physiotherapists. We conducted a questionnaire survey on professionalism, job satisfaction, and business performance. We then performed a correlation analysis.

Results: The highest 'compliance of professional organization' in professionalism, the lowest 'vocation awareness of the profession'. In job satisfaction, the highest satisfaction was reported for 'supervisor', and the lowest satisfaction for 'duty'. Professionalism and job satisfaction/job satisfaction and job performance showed a clear positive correlation, and professionalism and job performance showed a weak positive correlation.

Conclusion: The results of this study indicate that, in order to improve the job performance of the physical therapist, it is necessary to improve professionalism and job satisfaction. Physical therapists should improve their professionalism in order to improve job performance. In addition, research to improve job satisfaction and job performance of the physical therapist should be continued.

Keywords: Professionalism, Job satisfaction, Job performance

서 론

전문직은 특별한 사회적 욕구를 충족시키기 위해 가치와 기술, 기법, 지식 및 신념체계를 일상적으로 사용하는 집단을 말하며, 사회는 이 집단이 전문적인 욕구를 충족시키는 데 적합한 면허부여, 혹은 관련 서비스를 제공하기 위한 합법적인 근거로서 다른 인가방식을 통해 공식적이고 법률적인 인정을 한다. 따라서 전문가란 특별한 전문직 에 종사하고 있는 구성원으로 자격을 부여 받고 클라이언트 체계에 서비스를 제공하기 위해 그것의 실천, 지식 및 기술을 사용하고, 전문 직의 가치와 윤리강령을 고수하는 개인을 말한다.

$\mathrm{Hall}^{2}$ 은 여러 학자들의 주장을 종합하여 전문직의 속성을 구조적 측면과 태도적 측면, 조직적 측면으로 나누어 포괄적으로 이해하려 고 하였으며 전문 직업성을 전문조직의 준거성, 공공 봉사에 대한 신 념, 자기 통제에 대한 신념, 소명의식, 자율성 등 다섯 가지 태도적 속
성으로 구분하였다. 첫째, 전문조직의 준거성은 공식 및 비공식 동료 집단을 전문직으로서 자신의 업무에 필요한 생각이나 판단의 주된 원천으로 삼는다는 것이다. 둘째, 공공 봉사에 대한 신념은 전문직이 사회에서 필수적이라는 생각과 자신의 업무가 자신에게뿐만 아니라 공공의 유익이 된다는 관점을 말한다. 셋째, 자기 통제에 대한 신념은 자신의 전문적 업무 판단 시 동료 전문가가 최선의 적격자라는 신념 이다. 넷째는 자신의 업무에 대해 헌신하겠다는 소명의식이며, 다섯 째는 고객이나 전문인이 아닌 사람이나 조직으로부터 어떤 외부적 압력이 없이 자신이 결정을 내린다는 자율성이다.

의학의 발달, 노령화 사회의 가속화, 만성질환의 증가, 국내 병원시 장의 개방여부, 병원의 재정악화, 국민의 건강의식 향상에 따른 고급 의료서비스의 요구 증가 등의 다양한 환경 변화에 둘러싸여 있는 보 건의료 분야는 이러한 요구에 부합하기 위해 선진화된 치료기법, 효 율적인 경영, 현대화된 시설 등 많은 조건을 충족해야만 한다. 그 가
Received January 8, 2015 Received February 7, 2015

Accepted February 9, 2015

Corresponding author Jae Won Heo

E-mail1831317@hanmail.net
Copylight $(2015$ The Korean Society of Physical Therapy

This is an Open Access article distribute under the terms of the Creative Commons Attribution Non-commercial License (Http:// creativecommons.org/license/by-nc/3.o.) which permits unrestricted non-commercial use, distribution, and reproduction in any medium, provided the original work is properly cited.

- This study has received a funding of Sehan university. 
운데 가장 중요한 사항 중의 하나는 병원 인력에 대한 것이다. 특히 물 리치료사는 의사나 간호사와 함께 환자를 직접 대면하면서 의료서 비스를 제공하기 때문에 환자의 만족도에 큰 영향을 미친다. 따라서 의료서비스의 질을 높이고 병원수익의 증대에도 직간접적인 영향을 미치는 이러한 물리치료사들에 대한 이해와 관리는 병원내 인력관 리의 중요한 사항 중 하나이다.3.4

또한 물리치료사는 환자를 가능한 최대로 기능적인 면에서 완전 히 독립시켜 사회로 복귀시킨다는 재활의 목적을 달성하기 위하여 상담, 평가 및 치료하면서 재활 팀에서 핵심적인 구성원의 역할을 담 당하고 있다. 하지만 대체로 과도한 업무와 근무시간, 낮은 보수 등에 서 불만족을 가지고 있다.-7

일반적으로 성과는 '바람직한 결과를 달성하고자 하는 개인 혹은 조직의 활동이나 정확성, 완전성, 비용, 속도 등 미리 정해진 기준에 비추어 측정한 주어진 업무의 달성도' 등으로 정의된다. 그러나 이러 한 사전적 의미와는 별개로 실제 성과의 개념을 정의하고 측정하는 것은 쉽지 않은 일이다. 성과를 단일 차원으로 개념화할 경우 명확하 고 측정이 용이하나, 측정시점이나 우선순위 혹은 측정대상 집단의 이해관계에 따라 성과의 개념들이 각기 다르게 해석되는 문제가 발 생하기 때문이다. Beard와 Dess ${ }^{9}$ 는 기업의 성과는 복합적인 현상으로 서 다차원적인 측정을 위해서는 조직구조, 동기유발, 집단역학, 직무 충실화, 의사결정, 리더십, 목표설정, 계획수립 등과 같은 요인들에 대 하여 종합적으로 측정하고 평가해야 한다고 하였다.

전문직으로서 물리치료사의 역할이 중요시되고 있는 상황에서 전 문직업성에 대한 국내 연구들을 살펴 보면 사회복지사, 운동처방사, 임상간호사 등을 대상으로 하여 업무수행 정도, 조직몰입관계, 정체 성, 전문직업성관련 영향요인 등의 다양한 연구들이 이루어지고 있 다. 반면 국내 물리치료사들에 관한 연구들을 살펴보면 Cheon'은 물 리치료사의 일반적 특성과 근무실태를 조사하고 이들과 직무만족도 간의 관계를 조사한바 있다. 또한 $\mathrm{Ahn}$ 등10은 물리치료사의 일반적인 특성과 근무실태를 조사하고 이에 따른 직무만족과 직장애착의 정 도를 비교하였으며, Lim 등은 병원 근무 물리치료사의 특성을 고려 하여 이들의 조직시민행동에 영향을 미치는 요인을 규명하기 위해 직무특성, 전문직업성 그리고 집단응집성에 대해 연구 하였다. Lee 등 12 역시 대상자들을 전남 동부지역 물리치료사들로 한정하여 그들의 업무환경과 업무량에 대해 조사하고 이와 관련된 직무만족도를 연 구하였다.

이처럼 물리치료사의 업무와 관련된 몇몇 연구들이 이루어지고 있으나 다른 병원 전문직 종사자들에 관한 연구에 비해 다양한 접근 이 이루어지지 못하고 있는 실정이다. 따라서 본 연구에서는 물리치 료사의 전문직업성, 직무만족 및 업무성과를 분석하고 그 상관관계 를 파악하여 전문직으로서 물리치료사의 중요성을 확인하고 조직
내 물리치료사의 업무능력 향상을 위한 기초자료를 제공하자 한다.

\section{연구방법}

\section{1. 연구대상}

본 연구는 광주. 전남 지역의 일부 종합병원, 재활병원, 요양병원, 의 원 등에서 근무하고 있는 물리치료사를 대상으로 이루어졌다. 대상 자 선정은 지역 내 의료기관에 근무 중인 물리치료사들을 대상으로 무작위로 이루어졌으며, 설문에 앞서 본 연구의 목적에 대해 충분히 설명하고 설문에 참여할 의사를 밝힌 자로 하였다. 설문방식은 설문 에 참여할 의사를 밝힌 물리치료사가 근무하는 기관에 직접 방문하 여 배포 후 회수하거나 부득이한 경우 전자우편을 통해 진행하였다. 설문지는 200 부를 배포하여 불성실한 응답을 제외한 148 부를 대상 으로 분석하였다.

\section{2. 연구방법}

\section{1) 측정지표}

(1) 전문직업성

전문직업성이란 클라이언트에게 서비스를 제공하는 데 있어 자신이 활용할 수 있는 전문직에 대한 지식, 기술 및 자격과 그 가치와 윤리 를 고수하는 태도와 행동을 말한다.1

본 연구에서 사용한 전문직업성 측정도구는 Hallo이 개발한 Professionalism Inventory Scale을 기반으로 하여 Snizek ${ }^{13}$ 과 Baek 등 ${ }^{14}$ 이 수정 한 내용을 사용하여 측정하였다.

설문 내용은 준거성 5 문항, 공공서비스에 대한 신념 5 문항, 자율성 5 문항, 자체규제에 대한 신념 5 문항, 소명의식 5 문항 등 총 25 문항으 로 구성되어있으며, Likert5점 척도 5점 '매우 그렇다', 1점 '전혀 그렇지 않다로 부여하여 측정하였다. 점수가 높을수록 전문직업성이 높은 것을 의미한다.

(2) 직무만족

직무만족은 직무와 직무조건과 관련하여 형성되는 것으로써 자신의 직무에 대한 평가 혹은 직무경험을 통해 느끼게 되는 즐거운 혹은 긍 정적인 감정의 상태로 정의된다. ${ }^{15}$

본 연구에서 사용한 직무만족 측정도구는 Flippo와 Seberhagen의 직무만족 요인과 물리치료사의 직무만족에 관한 선행연구들에서 사 용한 것을 참조하여 연구 목적에 맞게 변형하여 사용하였다. ${ }^{10,12,16}$

직무만족을 측정하기 위한 설문은 직무에 관한 사항 6 문항, 감독 에 관한 사항 8 문항, 보수에 관한 사항 5 문항, 승진에 관한 사항 5 문항, 동료에 관한 사항 5 문항, 기관에 관한 사항 5 문항, 이직에 관한 사항 4 문항으로 구성하였다. 측정은 Likert5점 척도로써 5점 '매우 그렇다', 1 
점 '전혀 그렇지 않다' 로 부여하여 점수가 높을수록 직무만족이 높 음을 의미한다.

\section{(3) 업무성과}

일반적으로 업무성과는 사회적, 생물학적 그리고 기계적 체계에도 적용될 수 있는 개념으로써 특정의 기대, 목적 혹은 목표의 달성 정도 를 의미한다. ${ }^{8}$

물리치료 업무성과 측정도구는 $\operatorname{Park}^{16}$ 과 $\mathrm{Kim}^{17}$ 이 구성한 업무수행 평가도구를 물리치료사에게 맞게 수정하여 사용하였다.

문항은 독자적 물리치료활동 9문항, 비독자적 물리치료활동 9문 항, 대인관계 활동 5 문항으로 총 23 문항이며, Likert 5 점 척도로 5점 '매우 그렇다', 1점 '전혀 그렇지 않다' 로 총점 23점에서 115점으로 점 수가 높을수록 물리치료 업무성과 정도가 높음을 의미한다.

\section{2) 자료분석}

본 연구를 위해 수집된 물리치료사들의 설문자료는 SPSS 18.0 프로 그램을 사용하여 분석하였다. 대상자들의 일반적 특성을 살펴보기 위해 빈도분석을 실시하였고, 전문직업성, 직무만족도, 업무성과를 알아보기 위해 평균과 표준편차를 이용하였다. 또한 전문직업성, 직 무만족도, 업무성과간의 관계를 알아보기 위해 Pearson 상관분석을 실시하였다.

Table 1. General characteristics

\begin{tabular}{|c|c|c|}
\hline Classification & Division & Distribution (\%) \\
\hline \multirow[t]{2}{*}{ Gender } & Male & $74(50.0)$ \\
\hline & Female & $74(50.0)$ \\
\hline \multirow[t]{5}{*}{ Age (year) } & $21-25$ & $40(27.0)$ \\
\hline & $26-30$ & $64(43.2)$ \\
\hline & $31-35$ & 19 (12.8) \\
\hline & $36-40$ & $20(13.5)$ \\
\hline & $>41$ & $5(3.4)$ \\
\hline \multirow[t]{2}{*}{ Marital status } & Married & $56(37.8)$ \\
\hline & Unmarried & $92(62.2)$ \\
\hline \multirow[t]{4}{*}{ Level of education } & College (3-year) & $73(49.3)$ \\
\hline & University (4-year) & $48(32.4)$ \\
\hline & Graduate student & $15(10.1)$ \\
\hline & Finish graduate school & $12(8.1)$ \\
\hline \multirow[t]{5}{*}{ Total career (year) } & $<1$ & $34(23.0)$ \\
\hline & $1-3$ & $25(16.9)$ \\
\hline & $3-5$ & 35 (23.6) \\
\hline & $5-10$ & $32(21.6)$ \\
\hline & $>10$ & $22(14.9)$ \\
\hline \multirow[t]{5}{*}{ Current career (year) } & $<1$ & $52(35.1)$ \\
\hline & $1-3$ & $33(22.3)$ \\
\hline & $3-5$ & $42(28.4)$ \\
\hline & $5-10$ & $8(5.4)$ \\
\hline & $>10$ & $13(8.8)$ \\
\hline
\end{tabular}

\section{결 과}

\section{1. 대상자의 일반적 특성}

전체 148 명의 대상자들에 대한 일반적 특성을 살펴본 결과 21 세에서 30 세까지가 전체의 $70.2 \%$ 로 대부분을 차지하였다. 3 년제 대학을 졸업 한 경우가 $49.3 \%$ 로 가장 많았으며, 대학원을 재학 중이거나 졸업한 경 우는 전체의 $18.2 \%$ 에 그쳤다. 또한 현 직장의 근무경력에서 5 년 이상 인 대상자는 $14.2 \%$ 로 나타났다(Table 1).

\section{2. 전문직업성, 직무만족 및 업무성과 분석}

대상자들의 전문직업성, 직무만족 그리고 업무성과에 대해 분석한 결과 전문직업성에서 '우리분야 종사자들이 높은 이상적 태도를 유 지하는 것은 바람직하다는 항목이 $3.80 \pm 0.79$ 점으로 가장 높은 점수 를 보였으며, '나는 정기적으로 전공 잡지를 읽는다'는 항목이 $2.16 \pm$ 1.06 점으로 가장 낮게 나타났다. 직무만족의 경우 '감독에 관한 사항' 에서 가장 높은 만족도를 보였고, '보수에 관한 사항'에서 가장 낮은 만족도를 나타냈다. 업무성과에 있어서는 '정확한 물리치료진단을 내린다' 항목이 $3.30 \pm 0.68$ 점으로 가장 낮았고, '환자나 보호자의 호 소를 경청하고 관심을 보인다 항목이 $3.99 \pm 0.63$ 점으로 가장 높게 나 타났다(Table 2).

\section{3. 전문직업성, 직무만족 및 업무성과의 상관분석}

대상자들의 전문직업성, 직무만족 및 업무성과 간의 상관성을 살펴 보기 위해 상관분석을 실시한 결과 전문직업성과 직무만족은 $\mathrm{r}=0.599, \mathrm{p}<0.001$ 로 뚜렷한 양의 선형관계를 보였으며, 전문직업성과

Table 2. Professionalism, job satisfaction and job performance of physical therapists

\begin{tabular}{ll}
\hline & Mean \pm SD \\
\hline Professionalism & \\
Compliance of professional organization & $3.09 \pm 1.11$ \\
Beliefs about public service & $3.33 \pm 0.93$ \\
Autonomy & $3.15 \pm 0.89$ \\
Beliefs about self-regulation & $3.11 \pm 0.89$ \\
Vocation awareness of the profession & $3.41 \pm 0.97$ \\
Total & $3.22 \pm 0.97$ \\
Job satisfaction & \\
Duty & $3.64 \pm 0.79$ \\
Supervisor & $3.62 \pm 0.83$ \\
Pay & $2.19 \pm 0.84$ \\
Promotion & $2.52 \pm 0.90$ \\
Colleague & $3.91 \pm 0.72$ \\
Institution & $3.10 \pm 0.95$ \\
Change job & $3.09 \pm 1.04$ \\
Total & $3.20 \pm 1.04$ \\
Job performance & $3.70 \pm 0.72$ \\
\hline
\end{tabular}


Table 3. Correlation between professionalism, job satisfaction and job performance

\begin{tabular}{lccc}
\hline & Professionalism & Job satisfaction & Job performance \\
\hline Professionalism & 1 & $0.60^{*}$ & $0.24^{*}$ \\
Job satisfaction & $0.60^{*}$ & 1 & $0.57^{*}$ \\
Job performance & $0.24^{*}$ & $0.57^{\star}$ & 1 \\
\hline
\end{tabular}

${ }^{*} p<0.01$.

업무성과 간에는 $r=0.238, p=0.004$ 로 약한 양의 선형관계를 나타냈 다. 직무만족과 업무성과 간에 $\mathrm{r}=0.565, \mathrm{p}<0.001$ 로 뚜렷한 양의 선형 관계를 보였다(Table 3).

\section{고 찰}

본 연구는 광주. 전남 일부 지역의 물리치료사들의 전문직업성, 직무 만족 및 업무성과를 분석하고 이들간의 상관관계를 알아보기 위해 이루어졌다.

첫 번째, 본 연구에서 대상자들의 전문직업성에 대해 조사한 결과 전체 25 문항의 최대 125 점에서 $80.49 \pm 8.56$ 점으로 중간 이상의 점수 를 보였다. 문항 평균은 $3.22 \pm 0.97$ 점이었으며, 가장 높았던 문항은 ‘우 리분야 종사자들이 높은 이상적 태도를 유지하는 것은 바람직하다' 라는 문항으로 '직업에 대한 소명의식' 영역에 해당하며, 가장 낮은 문 항인 '나는 정기적으로 전공 잡지를 읽는다'는 '전문조직의 준거성' 영 역에 해당한다. 이러한 결과는 물리치료사들 스스로 직업에 대한 소 명의식은 높으나 이를 위해 갖추어야 할 전문가로서의 준거성에 대한 노력은 부족하다는 것을 간접적으로 보여주는 것이라 생각된다. 물 리치료사의 전문직업성에 관한 선행연구들이 제한적이므로 이러한 결과를 다른 전문직인 간호사들에 관한 연구와 비교해 보면, Shin ${ }^{18}$ 은 임상간호사들의 전문직업성과 조직효과성의 관계에 대한 연구에 서 '직업에 대한 소명의식' 영역이 가장 높으며 '전문조직의 준거성' 영 역이 가장 낮은 것으로 보고하여 본 연구의 결과를 뒷받침한다. 또한 $\mathrm{Cha}^{19}$ 는 임상간호사의 전문직업성과 직무만족.조직몰입에 관한 연 구에서 '직업에 대한 소명의식' 영역이 두 번째로 높게 나타났으며, '전 문조직의 준거성' 영역이 가장 낮게 나타난 것으로 보고하여 본 연구 결과와 마찬가지로 '직업에 대한 소명의식'에 비해 '전문조직의 준거 성' 부분이 부족한 것으로 나타났다. 이러한 결과들과 비교할 때 세 부문항에 있어서 차이를 보이기는 하지만 물리치료사들과 간호사들 간에 전문직업성이 유사함을 알 수 있다. 일부 항목에서 차이를 보이 는 이유는 본 연구에서 사용된 전문직업성 척도가 주관적이고 내적 인 태도요소에 초점을 맞춘 척도이기 때문인 것으로 사료된다. 따라 서 이러한 평가는 객관적인 전문성에 관한 평가는 아니며, 대상자들 의 주관적인 태도임을 유의할 필요가 있을 것으로 생각된다.
두 번째, 본 연구에서 대상자들의 직무만족에 대한 조사결과 전체 항목 평균에서 $3.02 \pm 1.04$ 점으로 보통 정도의 만족도를 나타냈다. 동 료에 관한 사항', '직무에 관한 사항', '감독에 관한 사항'에서는 중간 이 상의 점수를 보인 반면, '보수에 관한 사항'과 승진에 관한 사항'에 있 어서는 낮은 만족도를 나타냈다. 이러한 결과는 Shim ${ }^{20}$ 이 물리치료사 의 사회심리적 요인과 관련한 직무만족 연구에서 전체항목 평균 3.16 \pm 0.10 점을 보였다고 밝힌 것과 유사하다. 또한 물리치료사의 근무실 태와 직무만족도에 관한 Cheon'의 1991년 연구에서도 평가도구에는 차이가 있었으나 전체항목 평균 5점 만점에 3.20점으로 보통 정도의 만족도를 보였다. 세부항목들에 있어서 업무의 중요성, 전문직 인정, 능력발휘, 동료와의 관계, 의사와의 관계 등의 항목에서 높은 만족도 를 보인 반면, 승진전망, 봉급의 적당성 등의 항목에서 보통 이하의 만 족도를 나타냈다. 이는 본 연구의 세부항목들에 대한 결과와도 많은 부분 유사함을 알 수 있다. 물리치료사들의 직무만족에 대한 사항들 은 보수와 승진 등과 같은 업무성과에 관한 보상적인 성격을 띤 부분 에 있어서 낮은 만족도를 보이고 있음을 알수 있으며, 이는 20년이 지 난 현재에도 크게 변하지 않은 것으로 추측할 수 있다. 이러한 결과는 앞으로 물리치료사들의 조직 내의 처우개선에 있어서 충분히 고려되 어야할 사항으로 사료된다.

세 번째, 대상자들의 업무성과에 대한 조사결과 평균 점수 최대 5 점에 대해 전체항목 평균 $3.70 \pm 0.72$ 점으로 주관적 평가 시 보통 이상 의 업무성과를 이루고 있는 것으로 나타나, 물리치료사들 스스로 업 무성과에 대해 비교적 높게 인식하고 있는 것으로 보인다. 이러한 결 과를 임상 간호사들의 업무성과와 비교하여 살펴보면, $\mathrm{Choi}^{21}$ 의 간호 업무성과에 관한 연구에서 전체 평균 $3.75 \pm 0.36$ 점을 나타냈으며, $\operatorname{Park}^{22}$ 은 간호사의 임파워먼트 수준과 직무스트레스 및 간호업무성 과에 관한 연구에서 간호업무 성과를 전체 평균 $3.73 \pm 0.38$ 점으로 보 고하였다. 이는 본 연구에서 나타난 물리치료사의 업무성과와 유사 한 결과로써 간호사의 업무성과와 물리치료사의 업무성과 정도에 큰 차이가 없음을 간접적으로 보여주는 것으로 생각된다.

마지막으로 본 연구에서 물리치료사들의 전문직업성과 직무만족, 업무성과 간의 관계를 살펴보기 위해 상관분석을 실시한 결과 전문 직업성과 직무만족 간에 그리고 직무만족과 업무성과 간에 뚜렷한 양의 선형관계를 보였으며, 전문직업성과 업무성과 간에는 약한 양 의 선형관계를 보였다. 이는 전문직업성이 높을수록 직무에 대한 만 족도가 높아지며, 전문직업성과 직무만족도의 향상을 통해 물리치 료사들의 업무성과를 향상시킬 수 있음을 의미한다. 이러한 결과는 전문직업성이 직무만족을 향상시키면서 업무를 수행하는데 영향을 미친다는 보고 내용들과 일치한다. ${ }^{23}$

전문직업성과 직무만족간의 상관관계에 대한 선행연구들을 살펴 보면 Kwon 등 24 이 작업치료사의 직무만족도 관련요인 연구에서 전문 
직업성 영역에 해당하는 자율성의 결여와 직무만족도간에 유의한 상관관계가 있다고 보고하였다. 또한 Lee ${ }^{25}$ 는 운동처방사와 물리치료 사의 전문직업적 정체성과 직무만족에 관한 연구에서 전문직업적 정 체성의 하부영역인 조직활용, 소명의식, 서비스 신념, 자율성 신념 등 과 직무만족의 하위영역인 동료, 보수, 직무, 감독, 근무환경 등의 상 관관계를 분석하였다. 그 결과 전문직업적 정체성의 일부 하위영역들 과 직무만족의 일부 하위영역들간에 상관관계가 있음을 보고하였 다. 간호사들의 경우 Kwon 등 26 의 연구에서 임상 간호사들의 전문직 업성과 직무만족에 관한 상관관계를 분석한 결과 통계적으로 유의 한 상관관계가 있는 것으로 나타났으며, 특히 전문직업성의 하위영역 인 자율성, 자체규제에 대한 신념, 직업에 대한 소명의식에서 정의 상 관관계가 있는 것으로 보고하였다. 또한 임상간호사의 전문직업성과 간호업무수행과의 상관관계에서 유의한 정의 상관관계가 있는 것으 로 보고하였고, 하위영역 중 전문조직의 준거성, 자율성, 자체규제에 대한 신념, 직업에 대한 소명의식이 각각 간호업무수행과 유의한 정 의 상관관계를 나타냈다고 보고하였다.

직무만족과 업무성과 간의 상관관계에 관한 선행연구들을 살펴보 면 Byun 등 27의 연구에서 직무만족, 직무소진, 조직시민행동, 업무성 과를 분석한 결과 직무만족과 업무성과 간에 유의한 상관관계가 있 음을 보고하였다 $(r=0.382)$. 또한 Yoo 등 28 의 연구에서도 간호사들의 임파워먼트, 업무성과, 직무만족의 관계를 연구한 결과 간호업무성 과와 직무만족 간에 유의한 상관관계가 있는 것으로 나타났다 $(\mathrm{r}=0.297)$. 다른 전문직을 대상으로 이루어진 이러한 선행연구들은 물리치료사의 전문직업성과 직무만족, 업무성과 간 상관관계가 있다 는 본 연구 결과를 뒷받침하고 있다.

본 연구에서는 대상자가 광주. 전남 일부 지역으로 제한 되었으며, 물리치료사들의 특성에 따라 세분화 되지 못하고 포괄적으로 선정 되었다. 또한 물리치료사들의 전문직업성과 직무만족, 업무성과에 대해 분석하고 그들 간의 상관관계만을 분석했다는 제한점이 있다. 그러나 본 연구를 바탕으로 물리치료사의 업무성과에 영향을 미칠 수 있는 전문직업성과 직무만족의 구체적인 하위영역들을 분석하는 연구들을 위한 기초자료로 활용될 수 있을 것으로 기대된다. 또한 물 리치료사의 업무성과를 향상시키기 위해 물리치료사스스로 전문직 업성을 배양하고 조직 내에서 그에 합당한 보상전략을 통해 직무만 족도를 개선하기 위한 연구들이 지속적으로 이어져야 할 것으로 생 각된다. 전문가로서의 물리치료사에 대한 다양한 연구들을 통해 물 리치료의 질적 향상을 이끌어 낼 수 있을 것으로 사료된다.

\section{ACKNOWIEDGEMENTS}

This study has received a funding of Sehan university.

\section{REFERENCES}

1. Barker RL. The Social Work Dictionary. Silver Spring, Maryland, NASW, 2003.

2. Hall RH. Professionalism and bureaucratization. Am Sociol Rev. 1968;63:92-104.

3. Kim HS, You SY, Kim MJ, et al. Direct care stress and job satisfaction in home care nurses. Korean J Women Health Nurs. 2004;10(3):261-5.

4. Park JS. The relationship of organizational and job characteristic, empowerment, job satisfaction and organizational commitment perceived by hospital administrative. Korean J of Health Policy \& Administration. 2004;14(1):65-88.

5. Huh YB. Job stress of physical therapists and organizational effectiveness. Inje University. Dissertation of Master's Degree. 2002.

6. Cheon JK. A study on the service performance and job satisfaction of physical therapists. J Kor Phys Ther. 1991;3(1):9-38.

7. Yi CH. Work-related stress among physical therapists. J Kor Phys Ther. 1990;2(1):65-74.

8. Stewart J, Walsh K. Performance measurement: When performance can never be finally defined. Public Money \& Management. 1994;14(2):45-9.

9. Beard DW, Dess GG. Corporate level strategy, business level strategy and firm performance. Acad Manage J. 1981;24(4):663-88.

10. Ahn SY, Kim WJ, Huh YB. Working conditions, job satisfaction and organizational commitment of physical therapists. J Kor Phys Ther. 2002; 14(4):308-22.

11. Lim JD, Lee KH, Kim WJ. Influence of individual and job characteristics, professional job perception, and group cohesiveness on organizational citizenship behavior of physical therapists in hospitals. KSHM. 2003; 8(2):70-92.

12. Lee HS, Song HK, Kim HN, et al. The study work conditions and job satisfaction of physical therapist in Jeonnam east area. J Kor Phys Ther. 2005;17(1):80-95.

13. Snizek WE. Hall's professionalism scale: An empirical reassessment. Am Sociol Rev. 1972;3:109-14.

14. Baek HC, Soo YU. Translation and validation of Korean version of Hall's professionalism inventory. J Korean Acad Nurs Admin. 2007;13(4):50915.

15. Locke EA. The nature and cause of job satisfaction : Hand book of industrial and organizational psychology. Chicago, Rand McNally, 1976.

16. Park SA. An exploratory study on the relationship between leadership style and performance in Korean nursing units. Perspectives in Nursing Science. 1990;4(1):45-61.

17. Kim WB. A study on the self-leadership and job satisfaction of workers in the companies. Younsei University. Dissertation of Master's Degree. 2001.

18. Shin HS. A study on the relationship between professionalism and organizational effectiveness of clinic nurses'. Hanyang University. Dissertation of Master's Degree. 2009.

19. Cha IJ. Clinical nurses' professionalism and job satisfaction, organization commitment. Hanyang University. Dissertation of Master's Degree. 2008.

20. Shim JH. A study on the effects of the social and psychological attributes of physical therapists on empowerment, job satisfaction and organizational commitment. Hanyang University. Dissertation of Doctorate Degree. 2009.

21. Choi YS. Effects of nurses' awareness on medical institution evaluation on nursing performance. Catholic University. Dissertation of Master's 
Degree. 2011.

22. Park JY, Choi MH. Study on empowerment level, job stress and nursing work performance. The Chung-Ang Journal of Nursing. 2004;8(1):83-99.

23. Boyt TE, Lusch RF, Naylor G. The role of professionalism in determining job satisfaction in professional services: A study of marking researchers. J Serv Res. 2001;3(4):321-30.

24. Kwon JA, Roh JH, Chang SJ, et al. Factors affecting the job satisfaction of occupational therapists. J Kor Occup Ther. 2007;15(1):117-30.

25. Lee SG. Effect of identity that exercise and physical therapist perceives on organization commitment, job commitment and job satisfaction.
Kyunghee University. Dissertation of Doctorate Degree. 2009.

26. Kwon KJ, Chu MS, Kim JA. The impact of nursing professionalism on the nursing performance, job satisfaction and retention intention among clinical nurses. J Korean Acad Nurs Admin. 2009;15(2):182-92.

27. Byun CB, Cho KS. The impact of job satisfaction and burnout on organizational citizenship behavior and job performance. TINA. 2012;8(3): 145-67.

28. Yoo SO, Lee SY, Han SO, et al. Empowerment, performance and job satisfaction perceived by hospital nurses. J Korean Acad Nurs Admin. 2006;12(3):406-14. 